requirements, differing methods of assessing disease, and variable stratification of known prognostic factors.

Single agent fluorouracil has a response rate of about $20 \%$ in patients with advanced stomach cancer. ${ }^{67}$ Various combinations of fluorouracil with adriamycin, mitomycin, and lomustine give response rates varying from $20 \%$ to $40 \%$ but cause greater toxicity.$^{67}$ Responses are usually partial and short and do not lead to long term survival. Responders have lived longer than non-responders in many of these studies, but this method of assessing the effect on survival of a particular regimen is inappropriate in these sorts of investigation. ${ }^{8} \mathrm{~A}$ recent report of combining etoposide, adriamycin, and cisplatin has claimed a response rate of $70 \%$, with $12 \%$ of patients attaining complete remission and operation becoming possible in $16 \% .^{9}$ These results await confirmation.

No combination of drugs has been proved to be superior to fluorouracil alone $e^{10-12}$ in terms of overall survival. The combination of fluorouracil, adriamycin, and mitomycin, although suggested as the ideal standard for future studies, ${ }^{12}$ has not increased survival compared with other combinations ${ }^{11}{ }^{13-15}$ or fluorouracil alone. ${ }^{11}$ No randomised trials have compared single agents with no treatment, but two studies have compared combination treatment containing fluorouracil with no treatment. ${ }^{16}{ }^{17}$ These failed to show that chemotherapy prolonged survival but can be criticised because the prognostic factors favoured the no treatment arms. Randomised trials have thus not proved that single agent or combination chemotherapy prolongs survival in patients with advanced stomach cancer.

Chemotherapy has been extensively investigated as adjuvant treatment after surgery. Two early trials suggested an improved survival with combination chemotherapy, ${ }^{18} 19$ and subsets of patients seemed to have benefited in some of the large Japanese trials. ${ }^{2021}$ Most randomised trials have failed, however, to show superiority of either single agent or combination chemotherapy over no treatment. ${ }^{22-27}$

Although chemotherapy has not been shown to prolong survival in patients with stomach cancer, fluorouracil is the current treatment of choice in patients with advanced disease who are symptomatic or who have difficulty in coping with not receiving treatment. Although response to fluorouracil occurs in only a few patients, the toxicity is modest and symptoms may be relieved. Unless symptoms cannot be alleviated by other means, patients should not receive chemotherapy for gastric cancer unless included in randomised trials or studies investigating new agents. Promising new treatments should be compared with no treatment.

The cure rate for stomach cancer has not improved in $\mathbf{5 0}$ years despite chemotherapy. ${ }^{28}$ New drugs or different treatments are urgently needed.

P I Clark

Research fellow M L SLEVIN

Consultant physician

Imperial Cancer Research Fund,

Department of Medical Oncology,

St Bartholomew's and Homerton Hospitals,

London ECIA 7BE

1 Office of Population Censuses and Surveys. Morality statistics by cause in England and Wales. London: HMSO, 1982.

2 Lundh G, Burn JI, Kolig G, et al. A cooperative international study of gastric cancer. Ann R Coll Surg Engl 1974;54:219-28.

3 Cullinan SA, Moertel CG. FAM therapy for advanced gastric cancer: an ideal standard? $\mathcal{f}$ Clin Oncol 1985;3:887-8.

4 Schein PS. The role of chemotherapy in the management of gastric and pancreatic carcinomas. Semin Oncol 1985;12(suppl 6):49-60.

5 Levi JA, Fox RM, Tattersall MH, Woods RL, Thomson D, Gill G. Analysis of a prospectively randomised comparison of doxorubicin versus 5-fluorouracil, doxorubicin and BCNU in advanced gastric cancer: implications for future studies. I Clin Oncol 1986;4:1348-55.
$6 O^{\prime}$ Connell MJ. Current status of chemotherapy for advanced pancreatic and gastric cancer. $\mathcal{F}$ Clin Oncol 1985;3:1032-9.

7 Earl HM, Coombes RC, Schein PS. Cytotoxic chemotherapy for cancer of the stomach. Clinics in Oncology 1984;3:351-69.

8 Anderson JR, Cain KC, Gelber RD. Analysis of survival by tumour response. $\mathcal{f}$ Clin Oncol 1983;1:710-9.

9 Preuser $\mathrm{P}$, Wilke $\mathrm{H}$, Achterrath W, et al. Advanced gastric carcinoma: a phase II study with etoposide (E), adriamycin $(\mathrm{A})$ and split course cisplatin $(\mathrm{P})=\mathrm{EAP}$. [Abstract.] Proceedings of the American Society of Clinical Oncology 1987;6:292.

10 Moertel CG, Engstrom P, Lavin PT, Gelber RD, Carbone RP. Chemotherapy of gastric and pancreatic carcinoma. A controlled evaluation of combinations of 5-fluorouracil with nitrosoureas and "lactones". Surgery 1979;85:509-13.

11 Cullinan SA, Moertel CG, Fleming TR, et al. A comparison of three chemotherapeutic regimens in the treatment of advanced pancreatic and gastric carcinoma. Fluorouracil vs fluorouracil and doxorubicin vs fluorouracil, doxorubicin and mitomycin. JAMA 1985;253:2061-7.

12 De Lisi V, Cocconi G, Tonato M, Di Costanzo F, Leonardi F, Soldani M. Randomised comparison of 5-FU alone or combined with carmustine, doxorubicin and mitomycin (BAFMi) in the treatment of advanced gastric cancer: a phase III trial of the Italian Clinical Research in the treatment of advanced gastric cancer: a phase III trial of
Oncology Group (GOIRC). Cancer Treat Rep 1986;70:481-5.

13 Douglass HO, Lavin PT, Goudsmit A, Klaassen DJ, Paul AR. An Eastern Cooperative Oncology Group evaluation of combinations of methyl-CCNU, mitomycin C, adriamycin and 5fluorouracil in advanced, measureable gastric cancer. $\mathcal{f}$ Clin Oncol 1984;2:1372-81.

14 Gastrointestinal Tumour Study Group. A comparative clinical assessment of combination chemotherapy in the management of advanced gastric carcinomas. Cancer 1982;49:1362-6.

15 Gastrointestinal Tumour Study Group. Randomised study of combination chemotherapy in unresectable gastric cancer. Cancer 1984;53:13-7.

16 Kingston RD, Ellis DJ, Powell J, et al. The West Midlands gastric carcinoma trial: planning and results. Clin Oncol 1978;4:55-69.

17 Rake MO, Mallinson CN, Cocking JB, et al. Chemotherapy in advanced gastric cancer: a controlled, prospective, randomised multi-centre study. Gut 1979;20:797-801.

18 Nakajima T, Fukami A, Takagi $K$, Kajtani T. Adjuvant chemotherapy with mitomycin $C$ and with a multi-drug combination of mitomycin $C, 5$-fluorouracil and cytosine arabinoside after with a multi-drug combination of mitomycin C, 5-fluorouracil and cy

19. Fujimoto S, Akao T, Itoh B, et al. Protracted oral chemotherapy with fluorinated pyrimidines as an adjuvant to surgical treatment for stomach cancer. Ann Surg 1977;185:462-6.

20 Imanaga $H$, Nakazato $H$. Results of surgery for gastric cancer and effect of adjuvant mitomycin C on cancer recurrence. World $\mathcal{f}$ Surg 1977;1:213-21.

21 Nakajima T, Fukami A, Ohashi I, Kajtani T. Long-term follow-up study of gastric cancer patients treated with surgery and adjuvant chemotherapy with mitomycin C. Int $\mathcal{J}$ Clin Pharmacol Biopharm 1978;16:209-16.

22 Dixon WJ, Longmire WP, Holden W. Use of triethylene thiophosphoramide as an adjuvant to the surgical treatment of gastric and colorectal carcinoma-ten year follow up. Ann Surg 1971;173:26-9.

23 Serlin O, Wolkoff TS, Amadeo JM, Keohn RJ. Use of 5-fluorodeoxyuridine (FUDR) as an adjuvant to the surgical management of carcinoma of the stomach Cancer 1969;24:223-8.

24 Engstrom PF, Lavin PT, Douglass HO, Brunner KW. Postoperative adjuvant 5-fluorouracil plus methyl-CCNU therapy for gastric cancer patients. Cancer 1985;55:1868-73.

25 Higgins GA, Amadeo J, Smith DE, Humphrey EW, Keehn RJ. Efficacy of prolonged intermittent therapy with combined 5-FU and methyl-CCNU following resection for gastric carcinoma. Cancer 1983;52:1102-12.

26 Fielding JWL, Fagg SL, Jones BG, et al. An interim report of a prospective randomised controlled study of adjuvant chemotherapy in operable gastric cancer BSCG. World I Surg 1983;7:390-9.

27 Nakajima T, Takahashi T, Takagi K, Kuno K, Kajtani T. Comparison of S-fluorouracil with ftorafur in adjuvant chemotherapies with combined inductive and maintenance therapies for gastric cancer. 7 Clin Oncol 1984;2:1366-71.

28 Howson CP, Hiyama T, Wynder EL. The decline in gastric cancer: epidemiology of an unplanned triumph. Epidemiol Rev 1986;8:1-27.

\section{Testing for HIV: the medicolegal view}

The annual representative meeting of the BMA earlier this year passed a motion to say that in certain circumstances doctors should be able to test for antibodies to the human immunodeficiency virus (HIV) without first gaining the patient's consent. Because of worries about the legality of testing without consent the BMA commissioned an opinion from Michael Sherrard QC and Ian Gatt. Their opinion, which I endorse and which is published in full on p 911, is that doctors could risk civil or even criminal proceedings if they test for antibodies to HIV without the patient's consent. This opinion will not be universally welcomed among the ranks of the BMA, and lawyers are divided on the subject. Some suggest that patients with a "perplexing presentation" might be taken to have given an implied consent to any tests designed to find out what was wrong with them.

There is no case law directly on the question of consent to testing, and the cases discussed by $\mathrm{Mr}$ Sherrard and Mr Gatt all turn on the question of consent to treatment rather than specifically to testing. But the doctor owes patients the same duty of care in everything he does for them in the course of exercising his professional skills. 
That duty includes making sure the patient's consent is properly informed. The Sidaway case confirmed that the patient does not need to be told everything, 'but the patient must understand the nature of the procedure the doctor proposes to carry out and the real risks attached. On this principle it would be hard to argue that a consent to the doctor's taking blood "for tests" would be a sufficient consent to allow a doctor to test for antibodies to HIV. With the severe consequences that could follow from a positive test result-for instance, the destruction of personal relationships and the refusal of life cover-the patient must be allowed an opportunity to refuse the test, particularly since identifying the infection will not enable the doctor to give lifesaving treatment.

Some lawyers might argue that since a responsible body of medical opinion favours testing without the patient's consent-that is, the doctors at the annual meeting-no doctor doing so would be held to be negligent. The law lords in the Sidaway case confirmed accepted medical practice as the test of whether or not a doctor has been negligent but affirmed the court's position as the final arbiter. Where there is a grave risk of serious consequences, the law lords said, doctors alone should not determine what a patient should be told. Doctors will thus be well advised not to test for antibodies to HIV without the patient's consent.

Clare Dyer

Legal correspondent, $B M \mathcal{F}$

1 Sidaway v Governers of Royal Bethlem Hospital (1985) 2 WLR 480.

\section{Consensus on preventing osteoporosis}

Osteoporosis is sometimes compared to hypertension; in both conditions irreversible damage is likely to have occurred if the doctor waits until symptoms have developed before starting treatment. Recently women (especially in the United States) have become aware of the need for preventive treatment for osteoporosis, but often their doctors have been reluctant to provide it. And the treatment offered varies enormously from one country to another, with some favouring hormones, others calcium, and yet others calcitonin or vitamin $\mathrm{D}$.

Last week an international symposium on osteoporosis was held in Aalborg, Denmark, and at the end of the meeting a panel of experts from Europe, the United States, and Australia debated and drew up a consensus statement on preventing and treating osteoporosis. This is published in full at $\mathrm{p} 914$.

Postmenopausal osteoporosis in women seems to be multifactorial in its aetiology; it is not just caused by loss of secretion of oestrogen at the menopause, since natural aging, the more sedentary lifestyle of the elderly, and inadequate nutrition all contribute.

Prevention may be primary or secondary. Primary prevention attempts to get the woman's bone mass as high as possible before the menopause. Two factors that are known to help are a high calcium intake in childhood and adolescence (which means persuading adolescent girls to drink skimmed milk rather than carbonated water) and exercise. Excess athleticism may be dangerous, however; distance runners who become amenorrhoeic quickly become osteoporotic.

Secondary prevention is with oestrogens. The meeting was unanimous and emphatic on this issue. No other treatment "stops the disease in its tracks." Prolonged analysis by the experts on the consensus panel convinced them that the overall effect of oestrogen treatment on mortality is likely to be beneficial rather than harmful. Hormone treatment given for about 10 years will delay by about 10 years the onset of symptoms of osteoporosis, such as fractures of the hip, and in practice this will delay their onset until close to the end of the expected life span.

The crunch question remains-which women should be treated? The consensus panel did not tackle this question, even when asked for advice from the floor during its press conference. One of its members, Dr Claus Christiansen, suggested that recent work by his own group was leading to a simple method of predicting women at high risk using biochemical tests and measurement of body weight. ${ }^{1}$ For now women and their doctors will have to continue to rely on the traditional risk factors-slender, small build, early menopause, and family history.

Even though many of the answers to doctors' questions are not yet in, the consensus statement covers much ground. The participants accepted that their conclusions had to be interim; another meeting will be needed before long. But consensus meetings of this kind are proving a useful balance to the excess claims of enthusiasts, providing as they do a clear division between what is known (on the basis of well designed research studies) and what is only surmised.

TONY SMITH

Deputy editor, $B M J$

1 Christiansen C, Riis BJ, Rødbro P. Prediction of rapid bone loss in postmenopausal women Lancet 1987; i:1105-7. 